MATEC Web of Conferences 22,00001 (2015)

DOI: $10.1051 /$ matecconf/ 20152200001

(C) Owned by the authors, published by EDP Sciences, 2015

\title{
Preface: The Integration of Books, Information and Archives against the
}

\section{Background of Information Technology}

\author{
Wenfang $L i$
}

Digital Library Department, Library of Huazhong University of Science and Technology, Wuhan, Hubei, China

In recent years, the reform pace of enterprises becomes faster and faster with the continuous development and improvement of the market economic system in China. More and more enterprises realize that an effective way to enhance the overall competitiveness of an enterprise is to strengthen the management efficiency of the enterprise. Therefore, the management significance of information, archives and books becomes even more prominent. It is a common problem for enterprise managers that how a closely related information integration mechanism should be established so as to provide the corresponding information basis for the development of information in enterprises.

Enterprises pay attention to the internal original knowledge information and the external latest knowledge information. After all, they not only are the quintessence of enterprises' social practices but also integrate the four features as a whole, namely extension, substitution, transmission and sharing. The integrated management on the internal and external information resources integration of an enterprise is undoubtedly feasible on this basis.

Standard specifications should be formulated during the implementation process. The information resource of an enterprise is enormous with various qualities and formats. So, the primary task of an enterprise is to formulate standard specifications. Secondly, it is suggested to start from the aspect of leader organizations. The enterprise information resource integration requires unified deployment and arrangement of leaders at different levels due to its wide range and large content. The orderly information resource integration can be realized by dividing the work of each department with objectives and plans.

From the perspective of the society, the enterprise information resource integration provides services for customers. Most of the service objects are design, production and management of enterprises. Service objectives are nothing more than 
the spread of scientific cultural knowledge, the storage of human cultural knowledge, the guarantee of the knowledge inheritance, the providing of scientific knowledge for all aspects of enterprises and the promotion of the social and enterprise development. Frankly speaking, the integration of enterprise information resources provides information services for enterprises. It is also the condition of the integration of information resources.

It is worth noting that certain technological means and methods should be used during the process. Integrate and optimize information resources through intentional selections after comparisons so as to combine all kinds of information resources together in the form of giving full play to functions. The next step is to establish an ordered management system because the integration of enterprise information resources should be maintained with certain rules and regulations. It is also the Identity

The structure of enterprise information is the same as its function. Both are collected, processed and then organized as relevant documental information. Information will inevitably go through such steps as classification, storage and statistics no matter it is processed, stored, input or output. Managements on information resources are actually identical and service procedures have the same characteristics. The only difference comes from their emphases. Both the internal original information and the external new information provide services for enterprises. Therefore, the integration of enterprise information resources is to the benefit of the information conversion as well as the unified leading and management of information resource departments on information.

Management efficiency of enterprises increases constantly with growing competitions. The construction of information resource integration has become an important factor influencing the enterprise management. The foundation for enterprise development can be only laid perfectly through in-depth digging and utilization of information resources. The integration of information resources is the cornerstone of the sustained and healthy development of enterprises. 